\title{
Coprolite research: archaeological and paleoenvironmental potentials
}

\author{
John C. Blong ${ }^{1}$ (D) $\cdot$ Lisa-Marie Shillito ${ }^{2}$ \\ Received: 21 July 2020 / Accepted: 16 November 2020 / Published online: 6 January 2021 \\ (C) Springer-Verlag GmbH Germany, part of Springer Nature 2021
}

Fecal material from archaeological sites, including discrete coprolites, dung and latrine deposits, can provide important high-resolution information on past environments and human behavior. Coprolites can provide fine-grained, at times even seasonal, information on changes in diet, health, and environment over time that typically cannot be obtained through other analytical methods (Bryant 1974; Reinhard and Bryant 2008; Riley 2008; Pearsall 2015:193; Shillito et al. 2020b). Researchers apply macro- and microscopic methods to coprolite studies including pollen, phytoliths, bones, parasites and more to address questions of past human behavior. The past decade has seen the introduction of biomolecular methods such as DNA and lipid biomarkers to compliment macroand microscopic methods. An emerging issue in coprolite research is how best to integrate these diverse datasets to provide a holistic interpretation of the past. This requires connecting specialists in different methodologies to encourage critical analysis of new data, to foster interdisciplinary collaborations, and to establish best-practice guidelines for the multiproxy analysis of coprolites. The increasing interest in coprolites as a source of paleogenetic information also raises ethical issues over how these materials should be approached by archaeologists. To address these issues, the authors organized a session at the 83rd annual meeting of the Society for American Archaeology held in Washington, DC, in April 2018. The Coprolite Research: Archaeological and Paleoenvironmental Potentials (CRAPP) session brought

This article is part of the Topical Collection on Coprolite Research: Archaeological and Paleoenvironmental Potentials

John C. Blong

john.blong@wsu.edu

1 Department of Anthropology, Washington State University, Pullman, WA, USA

2 School of History, Classics and Archaeology, Newcastle University, Newcastle upon Tyne, UK together international coprolite researchers with a variety of methodological expertise applied at temporally and spatially diverse archaeological sites around the world, with case studies from North and South America, Europe and West Asia. The papers compiled for this volume were contributed by session invitees.

\section{A diversity of methods and global regions}

Two papers examine coprolites from hunter-gatherer groups in the Great Basin region of North America. Blong et al. (2020) combine macro- and microscopic analyses of animaland plant-derived material in Younger Dryas and early Holocene coprolites from the Paisley Caves, Oregon. This study presents evidence for a broad-based diet utilizing diverse landscapes around the caves, including the earliest direct evidence for consumption of whole rodent and several types of beetle. There is very little direct evidence for human diet during this early phase of human occupation of North America, and this study highlights the importance of plant and small animal resources in the human diet during this time. McDonough (2019) presents a multiproxy study of middle Holocene coprolites from Connley Caves, Oregon, the first human coprolite analysis for this time period in the region. Research indicates occupation in late summer/early fall by people eating a variety of plant and animal food items collected from ecologically diverse landscapes. This study identified dietary staples and expands our understanding of diet breadth for this period. McDonough also reports ova belonging to the family Taeniidae (tapeworm), potentially representing an early example of tapeworm infection in North America. Blong et al. and McDonough both provide new perspectives on hunter-gatherer diet and seasonal subsistence strategies during periods of regional climate and cultural change.

Moving south to the Colorado Plateau region of North America, Battillo (2019) presents results of plant macrofossil, 
pollen, and aDNA analysis of human coprolites from a 2000year-old midden feature at the Turkey Pen Ruin rock-shelter in Cedar Mesa, Utah, a low-intensity farming community. Maize (Zea mays) is known to have been a staple for the early Ancestral Pueblo population occupying the site. Battillo finds evidence for the consumption of wild resources, particularly weeds associated with agricultural fields, to supplement maize. This study presents unique evidence for consumption of corn smut (Ustilago maydis), an edible fungus that grows on maize. Battillo applies DNA analysis to identify several additional plant and animal food items that were not represented in the macro/microfossil records. This study shows that foraging occurred alongside agricultural practices providing additional calories and nutrients not available in maize. Many of the foraged foods were readily available in the same fields that were tended for maize, suggesting the creation of an anthropogenic ecological niche that influenced dietary choices. Battillo makes an important theoretical contribution by testing hypotheses rooted in optimal foraging models to evaluate human dietary decision-making.

In South America, Pucu et al. (2020) and Velázquez et al. (2020) present research from Mexico and Argentina, respectively. Pucu and colleagues studied coprolites from 1200 1400-year-old contexts at La Cueva de Los Muertos Chiquitos Cave, Mexico, integrating macroscopic and microscopic plant and animal analyses. This study found evidence for meals dominated by maize, as well as evidence for significant consumption of squash, beans, and agave. Pucu and colleagues also found evidence for the consumption of food items typically underrepresented in archaeological deposits, including rodent, Juniper berries, groundcherry, andsimilar to Battillo (2019) - corn smut. Dietary data are linked with previously published parasite data suggesting that parasitic infections were common and may have impacted health and nutritional intake. This study provides insight into prehistoric meals that are linked to regional ethnographically documented food types and preparation techniques, providing evidence for the continuity of dietary traditions over time. Pucu et al. link their results to recently published gut microbe aDNA results from the site, making a case that traditional coprolite analysis methods should be considered in tandem with cutting-edge genetic research to better interpret changes in gut microbiome over time.

Non-human coprolites from archaeological contexts can be used to reconstruct past environments and provide context for understanding human behavior. Velázquez and colleagues studied pollen in the exterior layer of camelid coprolites from Holocene contexts at semi-arid upland caves in Santa Cruz, Argentina. Velázquez and co-authors found that exterior coprolite pollen reflects local and regional pollen rain as well as pollen from plant material consumed by camelids. Variable pollen concentration between samples suggests coprolites were deposited in different seasons. When compared with pollen extracted from cave sediments, pollen in the outer layer of the coprolites contain more pollen diversity and better represent low-productivity (e.g., insect pollinated) taxa and, therefore, provide insight into local vegetation not achieved by sediment sample analysis. This is particularly important in arid regions where there often are not lakes or wetlands with well-preserved paleoenvironmental/pollen archives.

Coprolite researchers working in the UK and Europe have a long tradition of studying coprolites on a microscale in sediment thin section, with extensive work on animal dung to address questions such as fuel use and animal management. Two papers in this volume look at animal dung in different settings. Portillo et al. (2020) review research at early Holocene settlements on the semi-arid Konya Plain of Central Anatolia. In these contexts, coprolites are often present as aggregates, trampled layers, ash, or disaggregated and mixed into sediments. Research by Portillo and colleagues incorporates analysis of dung spherulites, biomolecular analysis, thin-section micromorphology, and plant macrofossils, pollen, and phytoliths. These proxies are typically studied in blocks of sediment extracted from archaeological contexts, enabling high-resolution, in-situ analysis of coprolite material. An important part of this research program is ethnographic study of modern pastoral populations in the region coupled with experimental research. Égüez et al. (2020) also use a geoethnoarchaeological approach, in their study of coprolite deposits collected from pastoral rock shelter sites in the Apennine Mountains of Italy. Égüez and colleagues analyze sediment samples collected from the floor of historic transhumance pastoral sites, incorporating micro-scale sediment analysis, stable isotope analysis, and phytolith, pollen, and nonpollen palynomorphs analyses. This research is focused in the mountains where relatively few studies of this kind have been conducted. Analysis revealed dung embedded in the rockshelter floors providing information about foddering strategies, intensity of occupation, and local environment. The multiproxy data generated by this study is compared with ethnographically documented pastoral land-use strategies to reconstruct seasonal transhumance pastoral patterns.

The study of parasite remains from coprolites has flourished in the past several decades. Camacho and Reinhard (2020) review the trajectory of research in this area and present new analysis of human parasitic infections recorded in coprolites from Ancestral Pueblo (0-1350 AD) sites of the Turkey Pen Cave, Salmon Ruins, and Aztec Ruins in the four corners of the region of the Colorado Plateau. Camacho and Reinhard assess pinworm (Enterobius vermicularis) prevalence using a pathoecology approach that considers both environmental and cultural factors that may affect parasitic infections (following Reinhard and Bryant [2008]). Using this approach, Camacho and Reinhard found that previous analysis of pinworm infections at the study sites were underestimated and that Ancestral Pueblo populations had 
significant pinworm infections. Individuals with the highest pinworm loads likely exhibited health impacts from pinworm infection, offering a window into the health and lifestyle of prehistoric inhabitants of the Colorado Plateau. This paper is an excellent example of the long history of collaboration between North and South American parasite researchers. Camacho and Reinhard demonstrate that the epidemiological and pathoecological approach should serve as a model for future parasite studies.

\section{Towards standardized methodologies and understanding bias}

In one sense, coprolite processing methods are fairly standardized, with many researchers in this special issue following the rehydration/screening/chemical separation of microfossils approach established by Callen and Cameron (1960) and Bryant (1974). However, there are variable approaches to sampling coprolites, and there have been few studies to measure the effect of sampling on resulting data. Beck et al. (2019) make an important methodological contribution by testing variations in pollen content from samples collected at different locations on coprolites from the Hinds Cave in the Lower Pecos region of Texas. This study found differences in pollen preservation, the number of taxa represented, pollen concentration, and pollen frequency in $1 \mathrm{cc}$ samples collected at different locations on the same coprolite. These findings have significant implications for interpreting intentional consumption. As Beck and colleagues discuss, distinguishing whether a pollen type represents intentional consumption typically depends on whether it reaches a certain threshold established by the researcher, for example, $4 \%$ for insect-pollinated taxa (Reinhard et al. 1991), or $40 \%$ for wind-pollinated taxa (Bryant 1977), or a concentration of 100,000 grains per gram of coprolite sample (Sobolik 1988). Beck et al. suggest that studies based on small, single-point subsamples can produce biased pollen data sets that may affect human behavioral interpretations. This study establishes the importance of collecting samples representing the length of a coprolite or, if this is not possible, recognizing that discrete, small-volume samples may not be representative of the pollen content of the entire coprolite. This study also highlights the importance of multiproxy approaches, particularly the need to consider both pollen and plant macrofossil evidence when making interpretations of human behavior. Method standardization is an area we hope to focus on going forward and was the basis of other contributions, including the keynote.

Reinhard et al. (2019) contribute to methodological developments in coprolite analysis through the use of scanning electron microscopy (SEM) to image microscopic remains in coprolites from sites across the southwest region of North America. Reinhard and colleagues use SEM to identify a variety of dietary remains including plant cellular material, seeds, pollen, spores, phytoliths, arthropod remains, and bone, with the goal of investigating dietary components and taphonomic preservation in coprolites. This study found that lignin, sporopollenin, calcium oxalate crystals, and siliceous material all preserved well, even in cases where there was evidence for post-depositional organic decomposition. Of particular interest is diagnostic microscopic plant cellular material that is typically dissolved by acetolysis during pollen preparation, or through combustion in phytolith preparation, and is therefore not preserved. In contrast with most analyses that separate the various macro- and microscopic components prior to analysis and photography, SEM imagery can be used to illustrate components of the diet in a single image, in a similar way to thin section analysis, but at a much higher resolution.

Perhaps the most important takeaway of the Reinhard et al. paper is the conclusion that the condition of microremains observed in SEM provide insight into the overall organic preservation in coprolites that can be used to assess whether the sample should be prioritized for biomolecular analysis. These results are particularly useful with the move towards increasing biomolecular analytical techniques (e.g., aDNA) (Battillo and Fisher 2015; Borry et al. 2020; Shillito et al. 2020a). These methods have limited utility in some coprolites, hypothesized to be the results of taphonomic processes that result in poor aDNA preservation. Evidence for decomposition indicates the presence of fungi and bacteria, whose molecular signals may show up in metagenomic analysis. SEM can therefore be used to screen and prioritize samples for biomolecular analysis, with the assumption that gene sequences may be altered by the same processes that impact preservation. The methods outlined by Reinhard and colleagues can be used to select the best-preserved samples with the highest potential for aDNA preservation.

Vaughn Bryant, head of the Palynology Lab at Texas A\&M University, USA, was the keynote speaker for the CRAPP session. Many researchers, including several authors in this volume, developed a foundation in coprolite analysis in Bryant's lab. Bryant's keynote reviewed the history of coprolite research beginning with Buckland's (1829) coining of the term "coprolite" and the first report on human coprolite plant macrofossil contents by Harshberger (1896). The keynote highlighted Bryant's collaborations with Eric Callen, whose methodological approach to coprolite analysis had a lasting influence on the practice in North America today (Callen 1967; Callen and Cameron 1955). Bryant underscored new horizons in coprolite research that have significantly broadened the types of information that can be extracted from coprolites, including DNA, blood typing, isotopes, parasites, steroid and amino acid contents, and different types of imaging used to analyze/display coprolite remains. Bryant emphasized four questions below that still need to be addressed concerning the analysis and interpretation of coprolite remains. 
1) How do we quantify coprolite contents?

2) How much sample needs to be examined?

3) How do you know when you reach redundancy during analysis?

4) How many coprolites need to be examined per strata or site?

How do we quantify coprolite contents in a meaningful way that can aid in the interpretation of diet? The primary issue in quantifying coprolite contents is that coprolite remains represent a small fraction of the dietary input. Animal digestive systems are designed to physically and chemically break down dietary inputs, and material excreted in feces represents the last remnants of what was consumed (O'Meara 2014). Taphonomic issues are not unique to coprolites; however, dietary remains in coprolites have undergone unique taphonomic transformations that typically do not affect other archaeological materials and have been understudied in comparison.

In many of the studies in this volume, a qualitative assessment of the presence or absence of dietary remains is enough to provide important insight into diet and environments. However, as discussed in Blong et al. (2020), there are clear differences in the dietary implications of-for examplemore than 1,300 cattail (Typha sp.) seeds in a coprolite versus a single cattail seed in a coprolite. McDonough (2019) utilizes an ordinal scale of dietary data to assess patterns through cluster analysis. This approach can be used to mitigate issues of large disparities in counts from one coprolite to another. The diversity of macrofossil remains can be affected by the subsample size, with larger samples expected to have more diverse remains; however, as McDonough (2019) reports, this is not always the case. To avoid potential sample size bias, Battillo (2019) standardized the macrofossil sample size from each coprolite then fully separated and weighed all components to make data more comparable. However, fully separating and weighing takes time, and as Blong et al. (2020) note, there is typically residual fine-grained material that cannot be separated, creating a somewhat biased sample. In sum, the methods utilized in this volume are effective in aiding in the interpretation of diet but highlight the idiosyncrasies of managing coprolite data from one study to the next.

Plant material offers unique interpretive challenges; macroscopic plant fiber and seed can be preserved in identifiable states in coprolites, while epidermal material is typically not. Several studies in this issue focus on seed remains, as these are more likely to be preserved and are often identifiable to a low taxonomic rank. However, in addition to the digestive taphonomic processed described above, seed preservation can be impacted by seed morphology (e.g., presence/absence of a hard seed coat) and pre-consumption processing techniques. Epidermal material typically does not survive digestion, but Blong et al. (2020) provide information on epidermis consumption through phytolith analysis that can be used to assess the consumption of plant material not available through seed analysis alone. This again highlights the importance of looking at a wide range of proxies to aid in dietary interpretations.

A persistent issue in quantifying and interpreting pollen data from coprolites is distinguishing pollen representing intentionally ingested plant material from ambient pollen entering the digestive system through respiration, drinking water, etc. Typically, this is addressed by assessing the relative percentage and concentration of a pollen type, presence of aggregate pollen grains, congruence with plant macrofossils, and pollen production and dispersal for taxa that produced the pollen (Bryant 1974; Sobolik 1988; Reinhard et al. 1991; Reinhard et al. 2006). In addition, knowledge of plant processing prior to consumption can be important. For example, Battillo (2019) found very low levels of maize pollen in coprolites - despite maize macrofossils comprising $70 \%$ of total macrofossil weight- - likely because corn husks with residual pollen are removed prior to consumption. The criteria for establishing intentional consumption of plant material from coprolites are followed in several papers in a special issue (Battillo 2019, Blong et al. 2020; McDonough 2019). However, as Beck et al. (2019) discuss, the few studies directly testing the assumptions underpinning these criteria suggest a complex relationship between pollen consumption and quantity present in human fecal samples.

Bryant asks the question "how much sample needs to be examined?" The study by Beck et al. (2019) goes a long way towards answering this question by demonstrating that the most representative pollen data sets are derived from samples collected along the entire length of a coprolite and that point samples as small as $1 \mathrm{cc}$ will likely produce biased results. Beck and colleagues hypothesize that there will be similar data biases in other microfossil data sets (e.g., phytoliths, starch); however, this remains untested. Previous research indicates that fecal samples from different locations in the colon of a mummy provide variable plant macrofossil assemblages suggesting remnants of different meals (Reinhard and Hevly 1991). Assessing the expected variability in dietary signature linked to sample size for multiproxy studies is an important avenue for future research.

Bryant questioned how an analyst knows when they have reach redundancy in their data, and in a related question, how many coprolites need to be analyzed from an archaeological context to accurately characterize human diet for the time/ occupation represented. In general, previous coprolite studies have demonstrated that main dietary components are typically uniform within a series of 15-20 coprolites from an archaeological context, but that additional sample analyses do reveal some dietary diversity (Reinhard 1988:40; Reinhard and Bryant 1992). Battillo (2019) analyzed 44 coprolites from a midden deposited over 130 years, adding to previous studies 
of 52 coprolites from the same site and period. Battillo's study found evidence for consumption of two plant taxa not previously identified as dietary items. McDonough's (2019) analysis of 16 coprolites from occupations spanning $~ 2,500$ years provides evidence for the consumption of a wide variety of plant and animal resources. Given the incredible diversity in these samples, it is likely that additional analyses may provide more information, perhaps fleshing out the identified dietary clusters into more distinct groups. Blong et al. (2020) identified a diverse set of dietary remains in nine coprolites spanning 2000 years of occupation of the Paisley Caves. It is clear that a much larger sample is needed to achieve redundancy, but there are so few coprolite studies from Pleistocene occupations in North America that this information is still insightful. The ten samples in Pucu et al. (2020) not only support the importance of agricultural foods, but also additionally highlight dietary diversity not replicated in more than one sample. The results of this small number of samples are strengthened by comparing with a previous study of 43 coprolites at the same site that demonstrate dietary redundancy.

The research in this volume indicates that larger samples continue to provide data on dietary diversity, but that even small samples sizes can provide important data. We would argue that coprolite analysis provides dietary data at the scale of an individual, giving insight into diet variability and human choice, and that this is a benefit rather than a limitation. Future focus should be on how we can use dietary information from different lines of evidence to provide a multiscalar view of diet. Studies such as those of Portillo et al. (2020) look at coprolite deposits within the context of the wider site, in comparison with data derived from faunal and archaeobotanical studies.

Parasitological analysis requires a larger sample size than dietary analysis - parasites are typically only present in 1$30 \%$ of coprolites from a context-so a sample size of 50 for agriculturalists and 100 for hunter-gatherers is recommended (Reinhard and Bryant 1992). The papers in this issue demonstrate that insight into health can come from parasite data from as little as one sample (McDonough 2019). However, larger-scale studies like that of Camacho and Reinhard (2020) can address different questions regarding frequency and prevalence of parasitic infections.

Research focused on ancient gut microbe aDNA preserved in coprolites has a lot of potential. There are established links between microbiome and health in modern populations (Shreiner et al. 2015), and coprolite analysis plays a crucial role in understanding how human gut microbe composition has changed over time and how this links in with dietary diversity and modern health issues. There were several papers in the CRAPP session highlighting the application of cuttingedge biomolecular methods (e.g., aDNA, lipid, protein) to coprolite analysis that were not published in this issue. One of these studies, recently published by the authors (Shillito et al. 2020a), applied fecal lipid biomarker analysis to determine the origin of coprolites at the Paisley Caves, Oregon. Fecal biomarkers are a product of the digestive system of the organism that produced a coprolite and are influenced by diet and biochemical processes that occur in the organism's gut. Fecal biomarkers - in particular, fecal sterols and bile acidscan be diagnostic and used to distinguish whether fecal material was deposited from a human, porcine, herbivore, or carnivore source (Bull et al. 2002). Shillito and colleagues use fecal biomarker analysis to confirm human presence at Paisley Caves 14,100 years ago, not only confirming previous aDNA analysis of the same coprolites (Gilbert et al. 2008; Jenkins et al. 2012), but also providing evidence for post-depositional movement of human aDNA through the cave sediments resulting in false positive aDNA results on non-human coprolites. We know very little about how DNA moves through sediment, but the small number of studies looking at this problem suggest that DNA is mobile and DNA from external sources can contaminate coprolites buried in archaeological deposits (Green and Speller 2017). This study provides an example of exciting new applications of biomolecular methods to coprolite research. Studies like Shillito et al. (2020a) indicate that more research is needed to assess biomolecule taphonomy to assist in interpreting these new methods. As McDonough (2019) points out, there are limitations to how certain we can be that a coprolite was deposited by a human using macro- and microfossil analyses. More recent developments in fecal biomarker and aDNA analysis provide the means to identifying the origin of archaeological feces.

\section{Summary}

The papers in the CRAPP volume highlight the current state of the art in coprolite research and explore how newer highresolution information can be better integrated into broader analytical studies using more traditional forms of evidence. The research presented here demonstrates the varied remains that can be recovered from coprolites and the range of applications of coprolite data to archaeological questions. The papers in this special issue provide new important information on human subsistence, health, and the environmental context of human adaptation across the temporal and geographic periods studied.

Seasonality is a theme that is present in several of the papers, from Blong et al. and McDonough, Batillo et al. on human coprolites, to Eguez et al. on animal dung. These studies highlight the application of coprolite data used for finegrained recreations of past human behavior. Several studies in this issue use coprolite data to test expectations of archaeological or ethnographic models, but coprolites can also test models of human decision-making because they record 
human food choice over a period of 1 to 2 days (Battillo, 2017, 2019; Riley 2012). Coprolite studies highlight the complexity of agriculture and subsistence strategies, provide important data to better understand the transition from hunting and gathering to agriculture, and contribute to broader debates about human dietary decisions and the impact of humans on their environments. Novel data from coprolites also shows a great diversity in food choice, beyond simple binaries of wild/domestic and high/low calorie, and brings culture back into our understanding of food and human choice that can be contrasted against broader trends.

An emerging issue in coprolite analysis is integrating diverse datasets to provide a holistic interpretation of the past. This requires connecting researchers specializing in different methodological approaches to encourage critical analysis of new datasets and to foster interdisciplinary multiproxy research connections. The interdisciplinary, international CRAPP session made strides towards this goal, working to bridge regional/institutional disciplinary traditions. A goal we are working towards is establishing standardized bestpractice guidelines for the multiproxy analysis of archaeological feces.

We conclude by reaffirming the importance of ethics in coprolite studies. Fox and Hawks (2019) refer to a "bone bonanza" and critique the "factory-like approach to analyzing ancient DNA" from human skeletal remains in the past 5 years, as researchers rush to acquire and analyze human remains for high-profile genetic studies. Fox and Hawks stress that we need to strike a balance between "discovery" and safeguarding of cultural materials_- "irrevocable decisions continue to be made about the sampling of ancient specimens, guided by the immediate research interests of a few." Coprolite research has so far not been involved in discussions. We would argue that coprolites should be treated with equal care, and involving descendent groups is crucial when designing research. As we look to the future of coprolite studies, we see integration of multiproxy analytical methods and collaboration with indigenous communities to foster a holistic perspective of the past.

\section{References}

Battillo J (2019) Farmers who forage: interpreting paleofecal evidence of wild resource use by early corn farmers in the North American Southwest. Archaeol Anthropol Sci 11:5999-6016. https://doi.org/ 10.1007/s12520-019-00944-y

Battillo JM (2017) Supplementing maize agriculture in Basketmaker II Subsistence: dietary analysis of human paleofeces from Turkey Pen Ruin (42SA3714). Southern Methodist University, Dallas
Battillo JM, Fisher AE (2015) Reconstructing meat consumption through biomarker analyses of paleofeces. Ethnobiol Lett 6:111-113. https:// doi.org/10.14237/ebl.6.1.2015.401

Beck CW, Bryant VM, McDonough KN (2019) Evidence for nonrandom distribution of pollen in human coprolites. Archaeol Anthropol Sci 11:5983-5998. https://doi.org/10.1007/s12520-01900839-y

Blong JC, Adams ME, Sanchez G et al (2020) Younger Dryas and Early Holocene subsistence in the Northern Great Basin: multiproxy analysis of coprolites from the Paisley Caves, Oregon, USA. Archaeol Anthropol Sci. Archaeol Anthropol Sci 12:224

Borry M, Cordova B, Perri A, Wibowo M, Prasad Honap T, Ko J, Yu J, Britton K, Girdland-Flink L, Power RC, Stuijts I, Salazar-García DC, Hofman C, Hagan R, Samdapawindé Kagoné T, Meda N, Carabin H, Jacobson D, Reinhard K, Lewis C, Kostic A, Jeong C, Herbig A, Hübner A, Warinner C (2020) CoproID predicts the source of coprolites and paleofeces using microbiome composition and host DNA content. PeerJ 2020:e9001. https://doi.org/10.7717/ peerj. 9001

Bryant VM (1974) Prehistoric diet in Southwest Texas: the coprolite evidence. Am Antiq 39:407-420. https://doi.org/10.2307/279430

Bryant VM (1977) Preliminary pollen analysis of Hinds Cave. In: Shafer HJ, Bryant VM (eds) Archaeological and botanical studies at Hinds Cave, Val Verde County, Texas, vol 1. Texas A\&M University Anthropology Laboratory Special Series, Texas, pp 70-80

Buckland W (1829) On the discovery of coprolites, or fossil feces, in the Lias at Lyme Regis, and in other formations. In: Transactions Series 2 (3). London, pp 223-236

Bull ID, Lockheart M, Elhmmali M et al (2002) The origin of faeces by means of biomarker detection. Environ Int 27:647-654

Callen EO (1967) Analysis of the Tehuacan coprolites. In: Byers DS (ed) The prehistory of the Tehuacan Valley, Environment and Subsistence, vol 1. University ot Texas Press, Austin, pp 261-289

Callen EO, Cameron TWM (1955) The diet and parasites of prehistoric Huaca Prieta Indians as determined by dried coprolites. Proc R Soc Canada 5:51-52

Callen EO, Cameron TWM (1960) A prehistoric diet revealed in coprolites. New Sci 8:35-40

Camacho M, Reinhard KJ (2020) Pinworm research in the Southwest USA: five decades of methodological and theoretical development and the epidemiological approach. Archaeol Anthropol Sci 12:63. https://doi.org/10.1007/s12520-019-00994-2

Égüez N, Dal Corso M, Wieckowska-Lüth M, Delpino C, Tarantini M, Biagetti S (2020) A pilot geo-ethnoarchaeological study of dung deposits from pastoral rock shelters in the Monti Sibillini (central Italy). Archaeol Anthropol Sci 12:114. https://doi.org/10.1007/ s12520-020-01076-4

Fox K, Hawks J (2019) Use ancient remains more wisely. Nature 572: 581-583

Gilbert MT, Jenkins DL, Götherstrom A et al (2008) DNA from preClovis human coprolites in Oregon, North America. Science 320: 786-789

Green EJ, Speller CF (2017) Novel substrates as sources of Ancient DNA: prospects and hurdles. Genes (Basel) 8:180

Harshberger JW (1896) Purposes of ethnobotany. Am Antiq 17:73-81

Jenkins DL, Davis LG, Stafford TW, Campos PF, Hockett B, Jones GT, Cummings LS, Yost C, Connolly TJ, Yohe RM, Gibbons SC, Raghavan M, Rasmussen M, Paijmans JLA, Hofreiter M, Kemp BM, Barta JL, Monroe C, Gilbert MTP, Willerslev E (2012) Clovis age western stemmed projectile points and human coprolites at the Paisley Caves. Science 337:223-228. https://doi.org/10.1126/ science. 1218443

McDonough KN (2019) Middle Holocene menus: dietary reconstruction from coprolites at the Connley Caves, Oregon, USA. Archaeol Anthropol Sci 11:5963-5982. https://doi.org/10.1007/s12520-01900828-1 
O'Meara DP (2014) In: Flores JR, Paardekooper R (eds) Ruminating on the past. A history of digestive taphonomy in experimental archaeology. Sidestone Press, Leiden, pp 131-146

Pearsall D (2015) Paleoethnobotany: a handbook of procedures, 3rd edn. Routledge, New York

Portillo M, García-Suárez A, Matthews W (2020) Livestock faecal indicators for animal management, penning, foddering and dung use in early agricultural built environments in the Konya Plain, Central Anatolia. Archaeol Anthropol Sci 12:40. https://doi.org/10.1007/ s12520-019-00988-0

Pucu E, Russ J, Reinhard K (2020) Diet analysis reveals pre-historic meals among the Loma San Gabriel at La Cueva de Los Muertos Chiquitos, Rio Zape, Mexico (600-800 CE). Archaeol Anthropol Sci 12:25. https://doi.org/10.1007/s12520-019-00950-0

Reinhard K, Camacho M, Geyer B, Hayek S, Horn C, Otterson K, Russ J (2019) Imaging coprolite taphonomy and preservation. Archaeol Anthropol Sci 11:6017-6035. https://doi.org/10.1007/s12520-01900946-w

Reinhard KJ (1988) Diet, parasitism, and anemia in the prehistoric Southwest. Texas A\&M University, Texas

Reinhard KJ, Bryant VM (2008) Pathoecology and the future of coprolite studies in bioarchaeology. In: Stodder ALW (ed) Arizona St. Arizona State University, Tempe, pp 199-216

Reinhard KJ, Bryant VM (1992) Coprolite analysis: a biological perspective on archaeology. Archaeol Method Theory 4:245-288

Reinhard KJ, Edwards S, TR, DK (2006) Pollen concentration analysis of Ancestral Pueblo dietary variation. Palaeogeogr Palaeoclimatol Palaeoecol 237 (1):92-109

Reinhard KJ, Hamilton DL, Hevly RH (1991) Use of pollen concentration in paleopharmacology: coprolite evidence of medicinal plants. J Ethnobiol 11:117-132
Reinhard KJ, Hevly RH (1991) Dietary and parasitological analysis of coprolites recovered from Burial 5, Ventana Cave. Kiva 56:319-325

Riley T (2008) Diet and seasonality in the Lower Pecos: evaluating coprolite data sets with cluster analysis. J Archaeol Sci 35:2726-2741. https://doi.org/10.1016/j.jas.2008.04.022

Riley T (2012) Assessing diet and seasonality in the Lower Pecos canyonlands: an evaluation of coprolite specimens as records of individual dietary decisions. J Archaeol Sci 39(1):145-162

Shillito L-M, Blong JC, Green EJ, Van Asperen E (2020b) The what, how and why of archaeological coprolite analysis. Earth Sci Rev 207:103196

Shillito L-M, Whelton HL, Blong JC et al (2020a) Pre-Clovis occupation of the Americas identified by human faecal biomarkers in coprolites from Paisley Caves, Oregon. Sci Adv 6:eaba6404

Shreiner AB, Kao JY, Young VB (2015) The gut microbiome in health and in disease. Curr Opin Gastroenterol 31(1):69-75. https://doi. org/10.1097/MOG.0000000000000139

Sobolik KD (1988) The importance of pollen concentration values from coprolites: an analysis of Southwest Texas samples. Palynology 12: 201-214. https://doi.org/10.1080/01916122.1988.9989344

Velázquez NJ, Burry LS, Mancini MV, Fugassa M (2020) Palynological analysis of the outer parts of camelid coprolites: implications for vegetation reconstruction. Archaeol Anthropol Sci 12:58. https:// doi.org/10.1007/s12520-019-00969-3

Publisher's note Springer Nature remains neutral with regard to jurisdictional claims in published maps and institutional affiliations. 